\title{
Erratum to: Density-dependent effects of larval dispersal mediated by host plant quality on populations of an invasive insect
}

\author{
Adam A. Pepi ${ }^{1}{ }^{1} \cdot$ Hannah J. Broadley ${ }^{1} \cdot J^{\prime}$ oseph S. Elkinton ${ }^{1,2}$
}

Published online: 15 September 2017

(C) Springer-Verlag GmbH Germany 2017

\section{Erratum to: Oecologia (2016) 182:499-509 DOI 10.1007/s00442-016-3689-z}

There was a coding error in the original paper resulting in incorrect model parameter estimates and in some cases incorrect model conclusions. The error was the specification of logistic models (using the glm and glmer functions) in $R$ as cbind (survived, total) instead of cbind (survived, dead). The differences between the originally published and correct models of those affected are detailed.

\section{Results}

\section{Laboratory density manipulation}

The laboratory density manipulation model has different parameters, but the direction and significance of effects is unchanged. The following are the correct numbers: In the laboratory experiments, larval survival in cup trials significantly decreased with increasing conspecific density (log odds $\beta=-0.031, \chi^{2}=191.2, P<0.001$, Fig. 1$)$, and differed by tree species $\left(\chi^{2}=97.6, P<0.001\right)$ and measurement date $\left(\chi^{2}=34.0, P<0.001\right)$. Fitted survival probabilities (leastsquare means, from lsmeans package, Lenth 2016) were $31 \%$

The online version of the original article can be found under doi:10.1007/s00442-016-3689-z.

Adam A. Pepi

adampepi@gmail.com

1 Organismic and Evolutionary Biology, University of Massachusetts Amherst, Amherst, MA, USA

2 Department of Environmental Conservation, University of Massachusetts Amherst, Amherst, MA, USA for red oak, $40 \%$ for red maple, and $26 \%$ for apple, and $46 \%$ lower at 7-10 days than at 5 days.

\section{Field density monitoring}

The main model of the paper, from field density monitoring, of density-dependent larval dispersal, also has different parameters, but the direction and significance of effects is unchanged. The following are the correct numbers: In the field, proportion of larvae remaining on sample trees decreased significantly with increasing initial density in both years $(2014: \log$ odds $\beta$ : red oak $=-2.187$, red maple $=-4.553$, apple $=-2.114$, $\chi^{2}=11.1 P=0.032, R^{2} \mathrm{~m}=0.190, R^{2} \mathrm{c}=0.238,2015$ : $\log$ odds $\beta$ : red oak $=-6.792$, red maple $=-4.873$ apple $=4.708, \chi^{2}=22.5, P<0.001, R^{2} \mathrm{~m}=0.126$, $R^{2} \mathrm{c}=0.126$, Fig. 2), and differed significantly between tree species (2014: $\chi^{2}=20.9, P=0.005,2015: \chi^{2}=15.3$, $P<0.001$, Fig. 2). Fitted survival probabilities (leastsquare means) were $94 \%$ for red oak, $14 \%$ for red maple, and $43 \%$ for apple in 2014 , and $98 \%$ for red oak, $42 \%$ for red maple, and $98 \%$ for apple in 2015. Parametric bootstraps were used only for the tests of the effects of $\log$ density and tree species in 2014, and all others were conducted using Wald Chi square tests because of the failure of parametric bootstraps and profile likelihood confidence intervals.

\section{Late larval predator exclusion}

For the 2013 results, the treatments in the late larval predator exclusion experiment model now become significant according to parametric bootstrap tests (i.e., models with treatment included as a predictor are significantly better than those without) in 2013; however, effects of individual treatment 


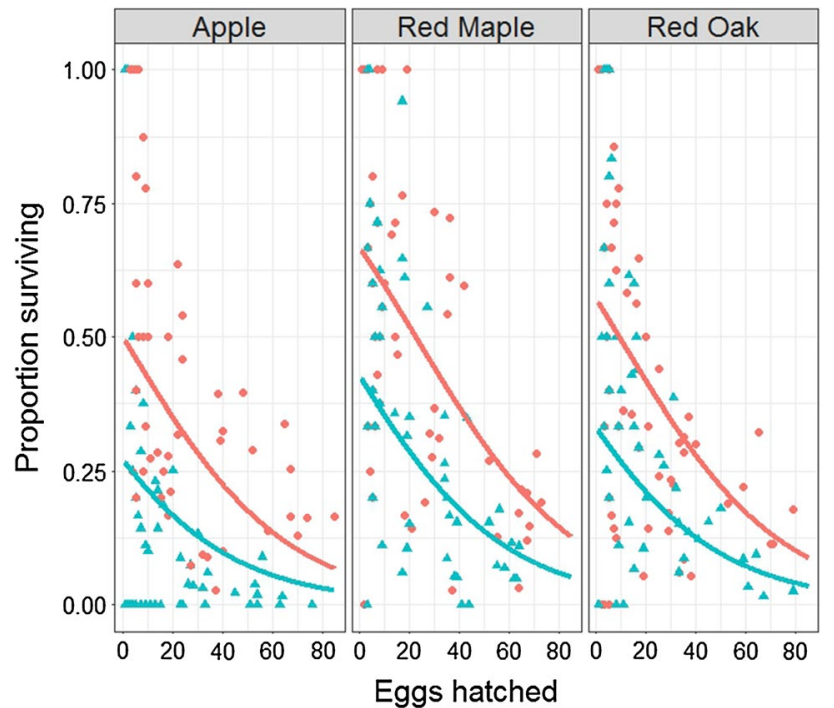

Trial length (Days) $=5$

Fig. 1 Updated figure of laboratory density manipulation experiment, showing corrected regression lines

levels are not significant according to 95\% profile likelihood confidence intervals. All effects remain non-significant in 2014. The corrected results, by years: in the larval predator exclusion experiment, models with treatment included were significantly better in 2013 but not 2014 (2013: $\chi^{2}=62.5$, $P<0.001$, 2014: effect: $\left.\chi^{2}=3.9, P=0.152\right)$, though treatment levels were not different in $95 \%$ profile likelihood confidence intervals in either 2013 or 2014 (2013: $\log$ odds $\beta$ : no predation or dispersal $=2.95$ [CI 0.84-1.48], no avian predation and full dispersal $=2.78$ [CI 0.84-1.48] full predation and full dispersal $=1.79$ [CI -0.81 to 3.07], $P<0.001$, 2014: $\log$ odds $\beta$ : no predation or dispersal $=2.95[\mathrm{CI}$ $0.34-2.07]$, no avian predation and full dispersal $=2.78$ [CI -0.04 to 0.42$]$, full predation and full dispersal $=1.36$ [CI -0.03 to 0.47$])$.

\section{Foliar quality}

The foliar quality models are changed. The main changes are that the effects of $\mathrm{pH} 10$ oxidative phenolics on dispersal are no longer significant in either year, carbon-nitrogen ration is now significantly related to dispersal in 2014, and the 2015 models of percent nitrogen and percent carbon fail to converge. The corrected results are summarized in the corrected Table S3, and a plot of the relationship of carbon-nitrogen ratio to larval survival rates in 2014 in Fig. 3.
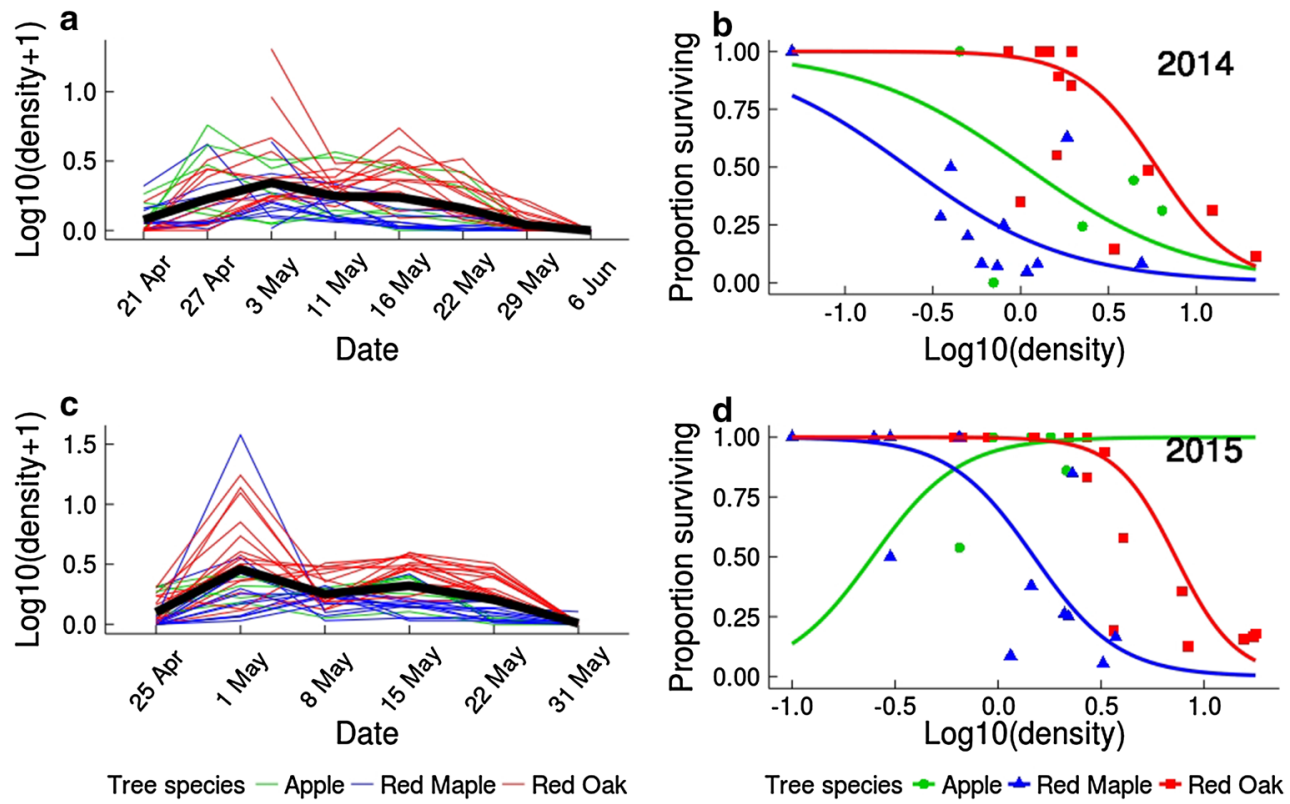

Fig. 2 Updated figure of field monitoring experiment, showing corrected regression lines 
Table S3 Year, sample size, slopes, marginal r-squared, conditional r-squared, likelihood ratio test chi squared values, parametric bootstrap significance tests, and Wald $\chi^{2}$ tests from models of effects of leaf quality on declines in larval density. P-values in bold are significant to the 0.05 level

\begin{tabular}{|c|c|c|c|c|c|c|c|c|}
\hline Variable & Year & $\mathrm{N}$ & $\beta$ (log odds) & $R^{2} m$ & $R^{2} c$ & $\chi^{2}$ & $\mathrm{P}$ & $\mathrm{P}_{\text {wald }}$ \\
\hline $\begin{array}{l}\text { Percent phenolics, } \\
\text { gallic acid equiva- } \\
\text { lents }\end{array}$ & 2014 & 26 & -0.040 & 0.1800 & 0.1800 & 9.349 & 0.824 & \\
\hline $\begin{array}{l}\text { Percent phenolics, } \\
\text { self-standard } \\
\text { equivalents }\end{array}$ & 2014 & 26 & -0.018 & 0.1798 & 0.1798 & 9.335 & 0.820 & \\
\hline $\begin{array}{l}\text { Proportion oxidative } \\
\text { phenolics }\end{array}$ & 2014 & 22 & -2.679 & 0.1958 & 0.1958 & 26.797 & 0.582 & \\
\hline $\begin{array}{l}\text { Percent phenolics, } \\
\text { gallic acid equiva- } \\
\text { lents }\end{array}$ & 2015 & 33 & 0.111 & 0.0554 & 0.1738 & 0.431 & N/A & 0.512 \\
\hline $\begin{array}{l}\text { Percent phenolics, } \\
\text { self-standard } \\
\text { equivalents }\end{array}$ & 2015 & 33 & 0.050 & 0.0559 & 0.1696 & 0.410 & N/A & 0.522 \\
\hline $\begin{array}{l}\text { Proportion oxidative } \\
\text { phenolics }\end{array}$ & 2015 & 26 & -2.799 & 0.0964 & 0.3182 & 1.329 & N/A & 0.249 \\
\hline Percent nitrogen & 2014 & 27 & -2.250 & 0.2965 & 0.2965 & 14.512 & 0.052 & \\
\hline Percent carbon & 2014 & 27 & -0.013 & 0.2220 & 0.2220 & 10.627 & 0.364 & \\
\hline $\begin{array}{l}\text { Ratio percent carbon: } \\
\text { percent nitrogen }\end{array}$ & 2014 & 27 & 0.855 & 0.3380 & 0.4426 & 16.189 & 0.024 & \\
\hline $\begin{array}{l}\text { Ratio percent carbon: } \\
\text { percent nitrogen }\end{array}$ & 2015 & 24 & -0.333 & 0.1177 & 0.1177 & 0.328 & N/A & 0.567 \\
\hline $\begin{array}{l}\text { Trichomes per linear } \\
\text { mm }\end{array}$ & 2015 & 33 & 0.120 & 0.1213 & 0.2203 & 2.840 & N/A & 0.092 \\
\hline
\end{tabular}

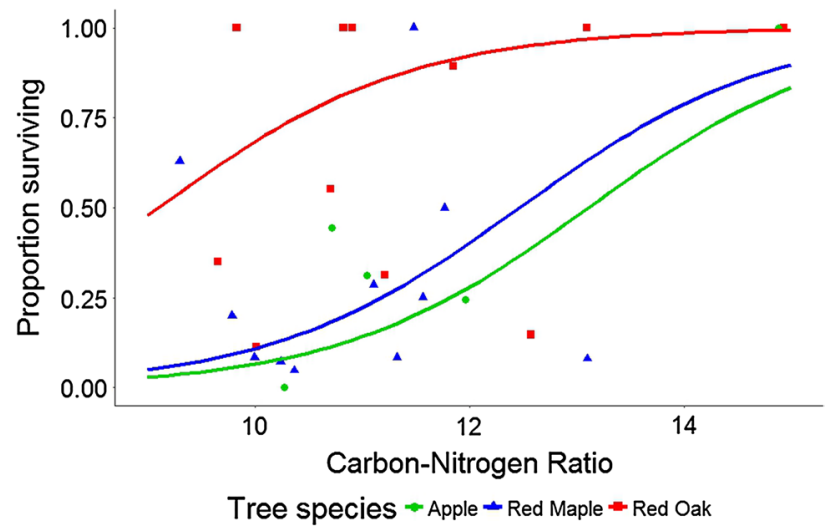

Fig. 3 Graph illustrating the relationship between carbon-nitrogen ratio and predicted larval survival in 2014

\section{Discussion}

The model results for the laboratory density manipulation and field monitoring model results have not changed significantly. The effect of treatment in models of late larval predation have become significant in 1 year, though the estimates of individual treatment level effects remain non-significant.
The $\mathrm{pH} 10$ oxidative phenolics are no longer significantly related to larval dispersal rates in 2015 as they were in the original model. This new result, however, does not change the main conclusions of the paper. We did not emphasize the importance $\mathrm{pH} 10$ oxidative phenolics because the evidence for its effect was quite weak, as is the new evidence for the effect of carbon-nitrogen ratio. The claim of the paper that larvae are responding to foliar quality rests on the larval dispersal from defoliated leaves experiments, the model results of which remain unchanged because it was specified correctly unlike the other logistic models.

In summary, the major conclusions of the paper, that 'larval dispersal is the dominant source of density-dependent larval mortality, may be mediated by induced changes in foliar quality, and likely regulates population densities in New England' (from the abstract) remain unchanged, though we now no longer have evidence to suggest that $\mathrm{pH} 10$ oxidative phenolics could be the active component of foliar quality driving larval dispersal.

\section{Reference}

Lenth RV (2016) Least-squares means: the R package lsmeans. J Stat Softw 69:1-33 